\title{
Thyroid Papillary Carcinoma in a Branchial Cleft Cyst-A Case Report
}

\author{
Chariton E. Papadakis', Alexandros Ladias' ${ }^{1}$, Theognosia S. Chimona ${ }^{1}$, Michail Gavriilidis ${ }^{2}$, \\ Maria Zisoglou ${ }^{1}$, Efklidis Proimos ${ }^{1 *}$
}

${ }^{1}$ ENT Department, Chania General Hospital, Chania, Greece

${ }^{2} 1^{\text {st }}$ Pathology Department, Medical School, University of Athens, Athens, Greece

Email: *efklidispr@hotmail.com

How to cite this paper: Papadakis, C.E., Ladias, A., Chimona, T.S., Gavriilidis, M., Zisoglou, M. and Proimos, E. (2017) Thyroid Papillary Carcinoma in a Branchial Cleft Cyst-A Case Report. Journal of Cancer Therapy, 8, 278-285. https://doi.org/10.4236/jct.2017.83023

Received: March 2, 2017

Accepted: March 28, 2017

Published: March 31, 2017

Copyright (c) 2017 by authors and Scientific Research Publishing Inc. This work is licensed under the Creative Commons Attribution International License (CC BY 4.0).

http://creativecommons.org/licenses/by/4.0/

\section{cc) (i) Open Access}

\begin{abstract}
Objective: Report a rare case of a thyroid papillary carcinoma situated within a branchial cleft cyst. Case presentation: A 40-year-old male was referred to our department for a lateral neck mass assessment. Physical examination revealed a solitary palpable, painless, moveable neck mass. Assessment included complete nasal, pharynx and larynx endoscopy, neck computed tomography, and fine needle aspiration biopsy. Treatment was surgical excision of the neck mass. Histopathology confirmed a branchial cleft cyst with papillary thyroid carcinoma growth at a site. A neck and thyroid ultrasound showed presence of thyroid gland nodules (one of which with micro calcifications). Thyroid fine needle aspiration biopsy performed, was high suspicious for malignancy (BETHESDA V). Patient underwent total thyroidectomy and histopathology revealed papillary thyroid carcinoma. Conclusion: Although rarely, it is possible to face an unexpected malignancy within a clinically benign neck lesion. A thorough diagnostic work-up enables early identification of aforementioned potential malignancy. A diagnostic dilemma that arises in such cases is between primary or metastatic disease and a thyroid carcinoma arising from ectopic thyroid tissue.
\end{abstract}

\section{Keywords}

Thyroid Cancer, Papillary Carcinoma, Branchial Cleft, Branchial Cyst

\section{Introduction}

Thyroid gland originates from primordial thyroid migration, which arises from the embryonic endoderm in the floor of primitive pharynx in the third week of embryonic life. Ectopic thyroid tissue is present in 7\% - 10\% of adults and can lie anywhere from the tongue base to the gland's final position. Possible sites of ec- 
topic thyroid are tongue $90 \%$, larynx, trachea, esophagus, mediastinum, pericardium, diaphragm and neck branchial cyst. [1] In some cases, ectopic is the only thyroid tissue present and may occur at any age from first month of life to 40 years. In $7 \%-10 \%$ of adults, ectopic thyroid tissue with normally located gland may co-exist. Very rarely existence of ectopic thyroid is identified at two or three different locations [2].

Branchial cysts are the result of branchial apparatus obliteration failure during the first stage of embryonic life and originate from the second (95\%), the first $(8 \%-10 \%)$, the third $(2 \%-8 \%)$ and the fourth (1\% - 2\%) branchial remnant [3]. They usually appear as asymptomatic neck swelling between second and fourth decades of life as a palpable, painless, moveable, neck mass along the anterior border of the sternocleidomastoid (SCM) muscle. Males and females are equally affected and there is occasionally a hereditary tendency. Twenty to $40 \%$ of patients report branchial cyst manifestation after an attack of pharyngitis, ear or dental infection, and many report temporary enlargement with or without tenderness during periods of upper respiratory tract infection [3]. Branchial cysts walls are thin and lined by squamous stratified epithelium overlying lymphoid tissue. Occasionally the cyst is lined with respiratory (ciliated columnar) epithelium. Differential diagnosis includes non-inflammatory lesions, such as malignant lymphadenopathy, lipoma, nerve sheath tumor, carotid body tumor, external laryngocele, cystic hygromas, and inflammatory lesions such as tuberculous node, and abscess. Lateral cysts of the neck containing malignant epithelium represent a diagnostic and therapeutic challenge. About $80 \%$ of lateral neck cystic masses seen in patients over 40 years of age are malignant, and the commonest cause of a malignant cystic swelling in the neck is a cystic lymph node metastasis, from a usually occult primary oropharyngeal carcinoma [4].

In the literature, there are very rarely reported squamous cell carcinomas arising in a branchial cleft cyst, known as branchiogenic cyst carcinoma or branchial cleft cyst carcinoma (BCCC) and more often metastatic squamous cell carcinomas with central cystic degeneration from an unknown primary site [5]. Papillary thyroid carcinoma (PTC) is the commonest form of well-differentiated thyroid carcinomas constituting approximately $85 \%$ of all cases. PTC is characterized by slow growth and indolent biological behavior, but with frequent cervical lymph node metastases. By the time of diagnosis PTC has already spread to cervical lymph nodes in $20 \%$ - 50\% of patients [6] [7].

We report a case of a thyroid primary carcinoma growth in a branchial cleft cyst and also share our diagnostic approach and treatment of this rare clinical entity.

\section{Case Report}

A 40-year-old male was referred to the Otolaryngology Department of Chania General Hospital for a left lateral neck swelling assessment. Physical examination revealed a solitary, palpable, movable, painless left sided neck mass with no other palpable lesions being present. Patient's medical history included only 
spherocytosis and no congenital anomalies were reported in his family history. Assessment included full ENT examination and complete nasal, pharynx and larynx endoscopy. Nose and nasopharynx evaluation was performed under local anesthesia, with a $0^{0}$ view, $2.7 \mathrm{~mm}$ diameter rigid endoscope [8]. Subsequently, endoscopic evaluation of the pharynx and larynx was performed in seated position with a flexible fiberoptic endoscope passed through the nose. Endoscopic evaluation of the aforementioned areas did not revealed any pathological findings. A neck computed tomography (CT) scan with three-dimensional reconstruction, in $5 \mathrm{~mm}$ axial, coronal and sagittal sections, before and after contrast infusion, showed the presence of a $3.3 \times 3 \mathrm{~cm}$ cystic lesion in the left lateral neck in contact to the left internal jugular vein and left sternocleidomastoid (SCM) muscle, compatible with branchial or thyroglossal duct cyst (Figure 1). Surgical excision of the neck mass was performed under general anesthesia and specimen's pathology revealed the presence of epithelial cells with lymphoid aggregations in the subepithelial lymphoid tissue structure. Growth of thyroid papillary carcinoma was present (cells with nuclear features diagnostic for papillary carcinoma) in a site (Figure 2). The neoplastic cells were stained positive for TTF-1, HMBE-1, CK19 and thyroglobulin, confirming thyroid origin (Figure 3).

Histopathology results imposed thyroid gland evaluation. Patient underwent thyroid gland ultrasound (U/S), fine needle aspiration (FNA) and blood tests.

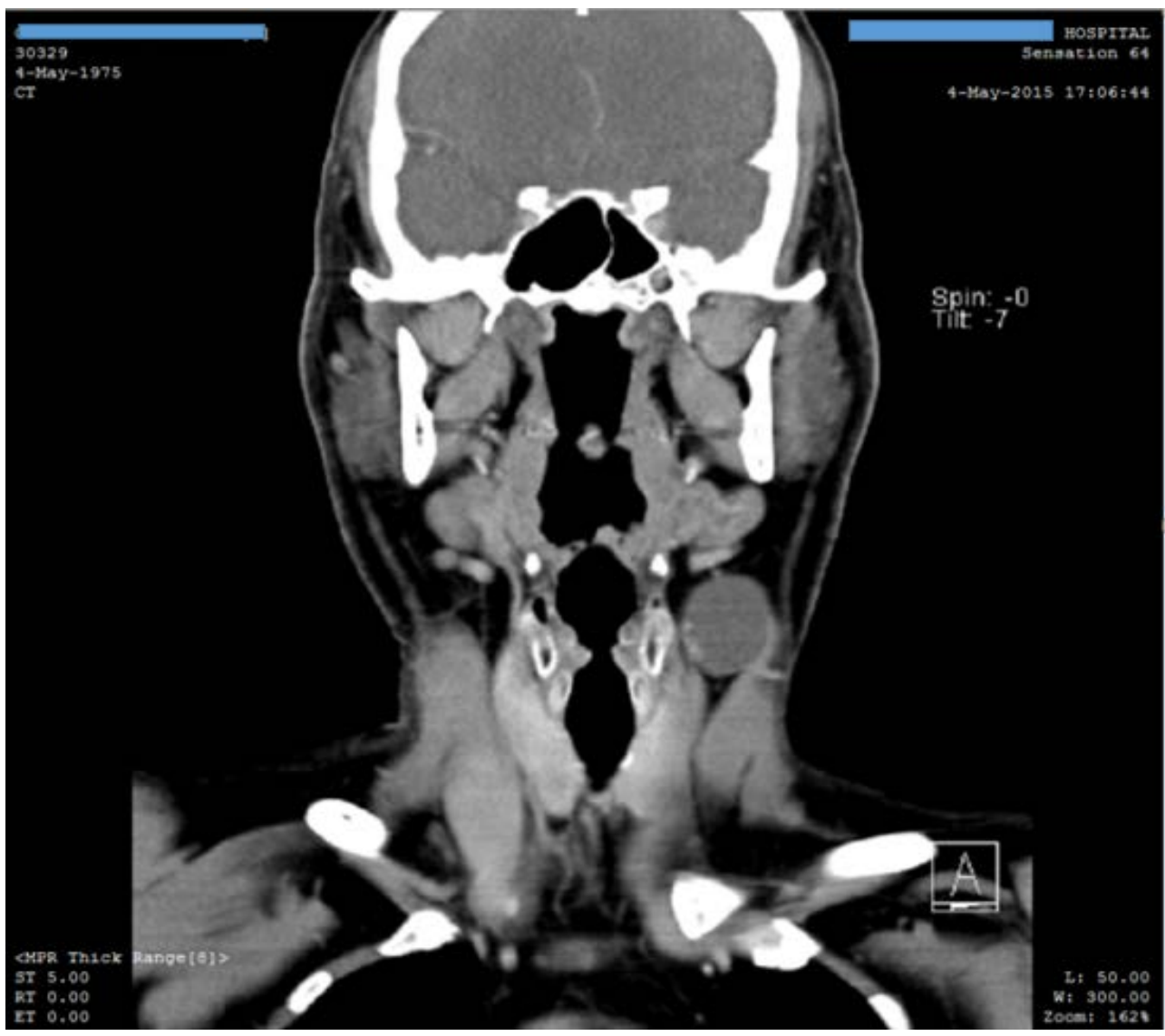

Figure 1. Cystic lesion in the left lateral neck in a coronal section CT with contrast infusion. 


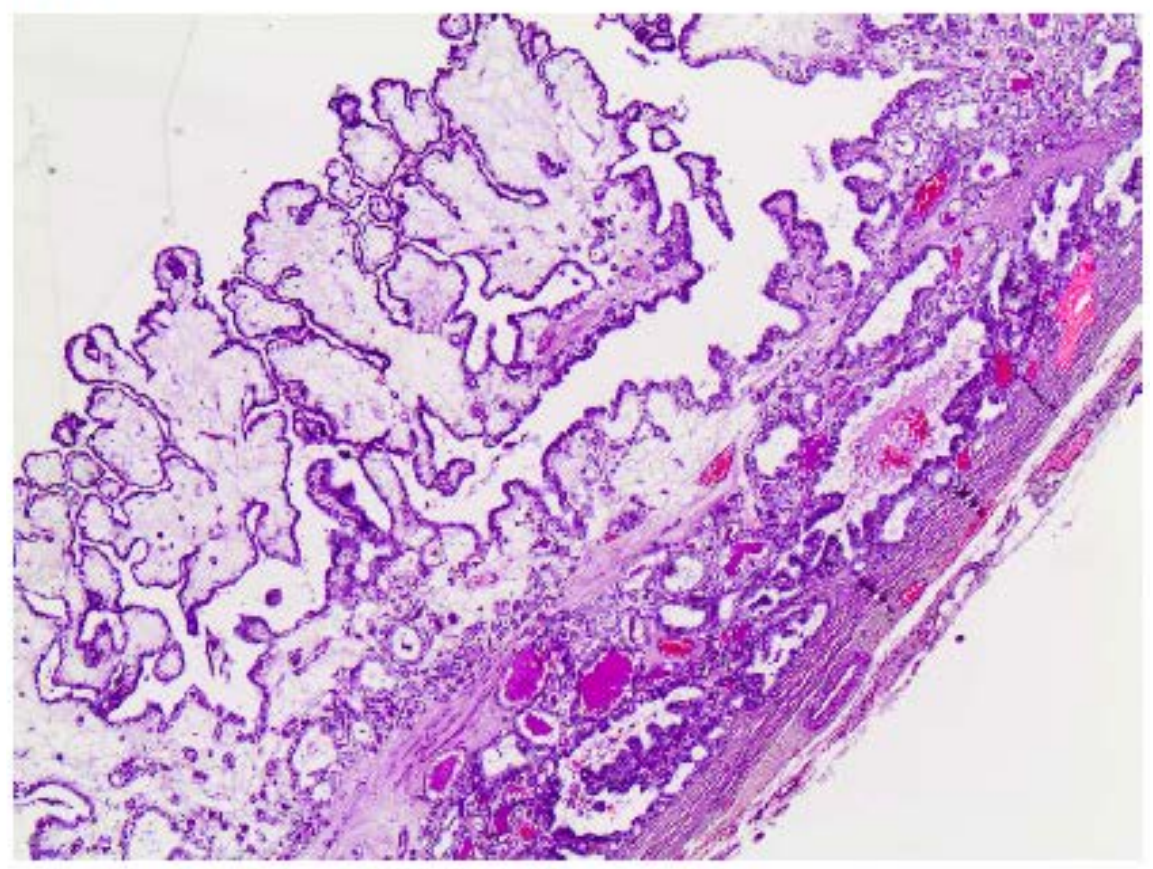

Figure 2. Branchial cyst wall with papillary thyroid microcarcinoma growth.

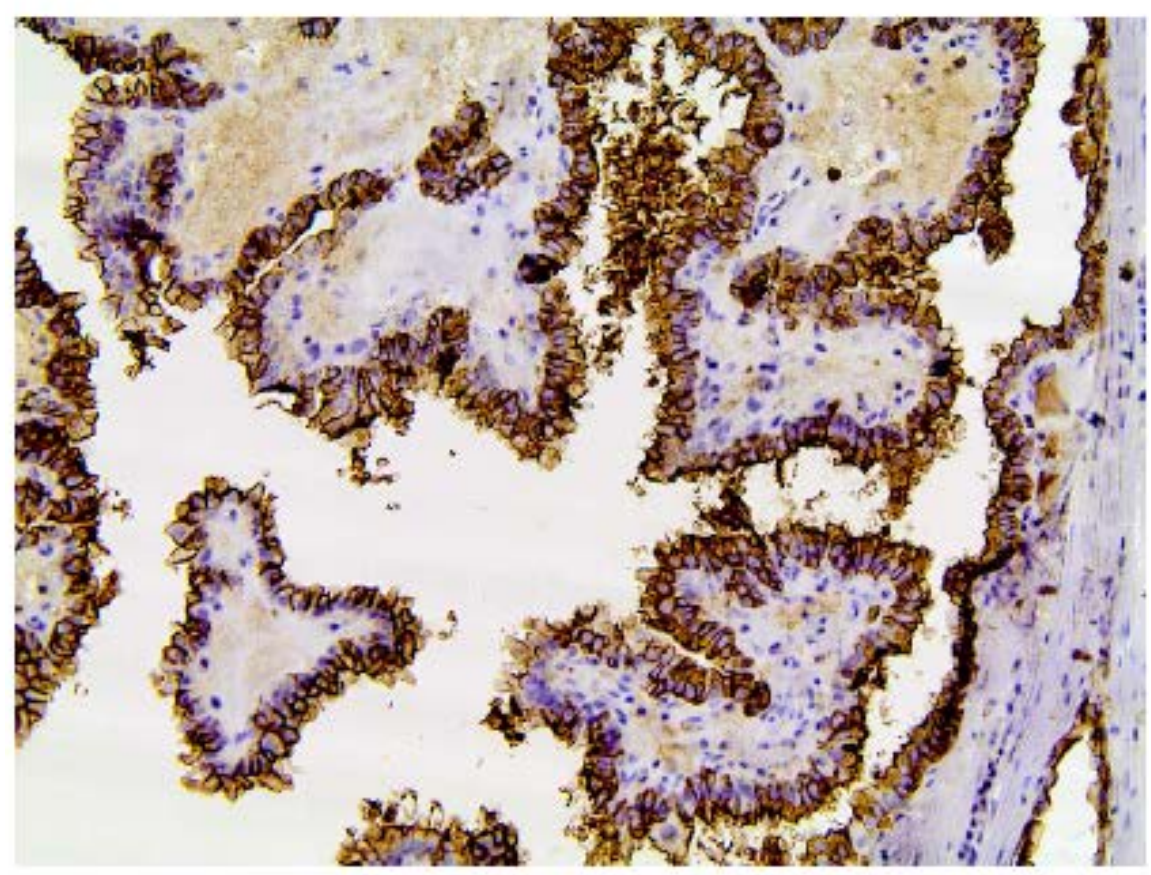

Figure 3. Intense cytoplasmic and membrane expression of HBME-1 protein in papillary thyroid microcarcinoma.

The presence of multiple infrasound nodes (maximum diameter $7.5 \mathrm{~mm}$ ), one of which with multiple micro-calcifications, was revealed. FNA biopsy was performed in the above-mentioned thyroid nodes and raised high suspicion for malignancy (Bethesda classification: V) [9]. Thyroid hormonal blood tests performed, including TSH, TG, PTH and calcitonin, were within normal limits. 
Patient underwent total thyroidectomy 4 weeks after initial surgery. Specimen's pathology revealed papillary thyroid carcinoma stage pT1a (TNM 2010). Postoperative hormonal blood tests performed, including TSH, TG, PTH and calcitonin, were again within normal limits. Radio-iodine ablative treatment was subsequently carried out.A dose of ${ }^{131}$ I was administrated in hypothyroidism and consequent whole body scan showed no areas of hyper fixation.

At the time of this case report writing, 36 months of follow up, patient remains in a very good condition with no clinical signs of recurrence and specifically, ultrasound imagine constantly negative, $\mathrm{C} / \mathrm{T}$ imagine negative for recurrence, distant or nodal metastasis, and set of hormonal blood tests as previously described always within normal limits.

\section{Discussion}

The most common benign lateral cervical cysts are branchial cleft cysts, epidermoid cysts, cystic hygromas, and teratomas. Cystic neck masses can also be related with metastases from oropharyngeal cancer. Rarely PTC presents as lateral neck cystic mass without palpable lesion in the thyroid gland [10]. A diagnostic issue that occurs in such a case is the fact that cystic mass may represent metastatic disease from a primary or a missed primary site, or thyroid cancer including PTC arising in ectopic thyroid tissue.

Literature confirms that $10 \%$ of lateral neck cysts in young patients represent metastases from occult thyroid carcinoma [10]. Thyroid papillary carcinoma gives frequent neck lymph node metastases, occasionally to lung and bones and rarely to other areas (skeletal muscles, ovaries, submandibular gland, sphenoidal sinus, pancreas, brain, adrenal glands) [11]. Previous case reports include also metastatic PTC in infratemporal fossa, pleural metastasis of thyroid carcinoma, skull base metastasis of PTC and PTC with synchronous asymptomatic esophageal squamous cell carcinoma (ESCC) manifesting as lateral cervical lymph node enlargement [12]. Cervical lymphadenopathy as a manifestation of sarcoidosis, mimicking metastatic PTC, has also been reported [13].

The PTC found in the branchial cyst in our case, was apparently an incidental finding. Lack of extra thyroidal invasion, negative lymph nodes with no evidence of metastasis and anatomical separation of the cyst and the thyroid are findings to support such a hypothesis. From our knowledge, this clinical entity is rare and is confirmed only in very few reports in the literature [14].

Preoperative diagnostic workup with imaging studies such as US, CT and magnetic resonance imaging (MRI) will determine lesion nature, anatomic location and relation with vital structures. Findings as intracystic enhanced elements and thickened or irregular outer walls in U/S or CT should raise suspicion for primary or metastatic malignancy including PTC [10]. Thyroid scintigraphy (with technetium-99) is very useful in diagnosis, especially in case of ectopic thyroid tissue. FNA cytology examination, plus thorough endoscopy of the upper respiratory system should be performed, for exclusion of metastatic or inflammatory adenopathy [3]. 
The gold standard of treatment is total surgical excision of the lesion with vital structures identification (such as jugular vein, internal and external carotid arteries and cranial nerves). Specimen's histopathology will confirm diagnosis.

After surgery, detailed clinical examination, laboratory tests and imaging studies are required. Hormonal blood tests have an important role in predicting prognosis. From previous studies, it has been shown that thyroglobulin measurements are the more reliable predictor of short term clinical outcomes than histopathologic staging criterion alone. Patients with biochemically complete response after treatment have low risk of developing disease recurrence [15]. Radioactive iodine ablative therapy completes management of this medical condition.

As described in literature, in all cases of thyroid cancers presented in ectopic site, such as a branchial cyst, the diagnostic dilemma that arises, includethe presence of occult primary carcinoma or the presence of metastatic disease. The up to date, management of these cases is similar (Imaging and FNAb, excisional biopsy of the branchial cyst and total thyroidectomy with or without complementary neck dissection). We believe that a rational preoperative approach of this diagnostic dilemma, as previously described in our case, will determine the necessity of a contemporaneous neck dissection and hence lead to the most appropriate, patient's treatment. Preoperative exclusion of metastatic disease, if possible, could prevent an unnecessary major operation such as selective neck dissection. Beyond the necessity for a complete early diagnosis, our proposal also includes patient's treatment at one stage (total thyroidectomy and branchial cyst surgical removal). Detailed histopathology with specimen's thin sections will reveal malignancy and confirm the initial diagnosis.

As a compendium, in case of a neck mass assessment, we suggest that besides ENT full examination, endoscopy and if appropriate FNAb, a neck U/S-including thyroid gland imaging - should be initially carried out. In case of pathological findings in the thyroid, patient should be referred to endocrinologist for thyroid gland assessment. At this stage we suggest that depending on U/S findings thyroid scintigraphy is necessary for thyroid lesions and for possible ectopic thyroid documentation and evaluation. This management, in case of ectopic thyroid tissue, will result in a one stage surgical removal of the lateral neck mass and the thyroid gland. In this case, the pathologist should be informed in detail for the possibility of ectopic thyroid tissue within the brachial cyst, in order to check thoroughly the appropriate sites for possible thyroid cancer growth. This practice offers a better and more effective treatment to the patient (less intraoperative risk and less delay in cancer treatment) and additionally an overall hospitalization cost reduction.

\section{Conclusions}

Differential diagnosis of a lateral neck cyst must include branchial cleft cysts which rarely may contain ectopic thyroid tissue that even more rarely may develop malignancy. Although biochemical blood tests and imaging studies help 
towards the diagnosis, histopathology for definitive results is required. Additionally, in cases of metastatic neck disease of unknown primary lesion site, benign congenital lesions should always be thoroughly inspected for the possibility of harboring occult carcinomas.

Conclusively, the aim should be the early detailed diagnosis which provides proper and the least burdensome treatment for the patient.

\section{References}

[1] Karras, S., Anagnostis, P., Noussios, G. and Pontikides, N. (2013) Thyroid Papillary Carcinoma Arising in Ectopic Thyroid Tissue within a Branchial Cleft Cyst. BMJ Case Reports, 4, 2013. https://doi.org/10.1136/bcr-2013-009312

[2] Batsakis, J.G., El-Naggar, A.K. and Luna, M.A. (1996) Thyroid Gland Ectopias. Annals of Otology, Rhinology \& Laryngology, 105, 996-1000. https://doi.org/10.1177/000348949610501212

[3] Zaifullah, S., Yunus, M.R. and See, G.B. (2013) Diagnosis and Treatment of Branchial Cleft Anomalies in UKMMC: A 10-Year Retrospective Study. European Archives of Oto-Rhino-Laryngology, 270, 1501-1506. https://doi.org/10.1007/s00405-012-2200-7

[4] Chimona, T.S., Tamiolakis, D., Proimos, E., Perogamvrakis, G., Korres, S.G. and Papadakis, C.E. (2007) Management of Second Branchial Cleft Abnormalities in Adults. B-ENT, 3, 39-43.

[5] Takashi, S., Touru, S., Hiroyuki, U., Kouki, H., Kouichi, A. and Katsunori, I. (2008) A Case of Squamous Cell Carcinoma Arising from Branchial Cleft Cyst. Oral Science International, 11, 135-140.

[6] Xu, J.J., Kwan, K. and Funq, K. (2013) Papillary Thyroid Carcinoma in a Lateral Neck Cyst: Primary of Ectopic Thyroid Tissue versus Cystic Metastasis. The Journal of Laryngology \& Otology, 127, 724-727. https://doi.org/10.1017/s0022215113001205

[7] Batori, M., Zullino, A., Pipino, R. and Eleni, C. (2012) Occult Papillary Thyroid Microcarcinoma Manifesting Only as a Symptomatic Lateral Cervical Mass: Report of a Case. Surgery Today, 42, 1010-1013. https://doi.org/10.1007/s00595-012-0186-9

[8] Lund, V.J. and Kennedy, D.W. (1995) Quantification for Staging Sinusitis. The Staging and Therapy Group. Annals of Otology, Rhinology \& Laryngology, 167, 17 21.

[9] Mondal, S.K., Sinha, S., Basak, B., Roy, D.N. and Sinha, S.K. (2013) The Bethesda System for Reporting Thyroid Fine Needle Aspirates: A Cytologic Study with Histologic Follow-Up. Journal of Cytology, 30, 94-99. https://doi.org/10.4103/0970-9371.112650

[10] Al-Ashaa, Y., Helfny, A.F., Joshi, S. and Abu-Zidan, F.M. (2011) Papillary Thyroid Carcinoma Presenting as a Lateral Neck Cyst. African Health Sciences, 11, 296-300.

[11] Morita, N., Morimoto, K., Yonezawa, K., Otsuki, N. and Nibu, K. (2013) Infratemporal Fossa Metastasis of Papillary Thyroid Cancer. Head Neck, 35, E119-E121. https://doi.org/10.1002/hed.21951

[12] Tunio, M.A., Al Asiri, M., Al-Qahtani, K.H., Aldandan, S., Riaz, K. and Bayoumi, Y. (2015) Skull Base Metastasis from Papillary Thyroid Carcinoma: A Report of Three Cases. International Medical Case Reports Journal, 8, 127-131. https://doi.org/10.2147/IMCRJ.S82792

[13] Salih, A.M., Fatih, S.M. and Kakamad, F.H. (2015) Sarcoidosis Mimicking Metastatic Papillary Thyroid Cancer. International Journal of Surgery Case Reports, 16, 
71-72. https://doi.org/10.1016/j.ijscr.2015.09.027

[14] Ruhl, D.S., Sheridan, M.F. and Sniezek, J.C. (2013) Papillary Thyroid Carcinoma in a Branchial Cleft Cyst without a Thyroid Primary: Navigating a Diagnostic Dilemma. Case Reports in Otolaryngology, 2013, Article ID: 405342. https://doi.org/10.1155/2013/405342

[15] Lango, M., Flieder, D., Arrangoiz, R., Veloski, C., Yu, J.Q., Li, T., Burtness, B., Mehra, R., Galloway, T. and Ridge, J.A. (2013) Extranodal Extension of Metastatic Papillary Thyroid Carcinoma: Correlation with Biochemical Endpoints, Nodal Persistence, and Systemic Disease Progression. Thyroid, 23, 1099-1105.

https://doi.org/10.1089/thy.2013.0027

Submit or recommend next manuscript to SCIRP and we will provide best service for you:

Accepting pre-submission inquiries through Email, Facebook, LinkedIn, Twitter, etc. A wide selection of journals (inclusive of 9 subjects, more than 200 journals)

Providing 24-hour high-quality service

User-friendly online submission system

Fair and swift peer-review system

Efficient typesetting and proofreading procedure

Display of the result of downloads and visits, as well as the number of cited articles

Maximum dissemination of your research work

Submit your manuscript at: http://papersubmission.scirp.org/

Or contact jct@scirp.org 